\title{
TESTING LEARNERS' ATTITUDES - VISUAL COMPONENTS OF TEXTS AS BRIDGES OR BARRIERS TO LEARNING
}

\author{
Christine Anthonissen \& Monica Kirsten \\ University of Stellenbosch
}

This article considers how visual images in texts may enhance or inhibit language learning. It draws on Kress and Van Leeuwen's (1996) work on the grammar of visual design, recognising that visual images form part of a powerful semiotic system that carries representational and connotative meanings in a manner comparable to that of words, sentences and larger textual units. It takes note of the ways in which new technologies have introduced more visual material in printed texts than was available before. And it reports on an investigation into the specific responses of Grade 10 learners to visuals of people featuring different characteristics. Eventually we need to develop learning materials where visuals facilitate and motivate language learning, and simultaneously facilitate the development of socially responsible values.

\section{BACKGROUND}

This article explores the impact of new communication technologies on selected social interactions and discourses in a multiracial-multicultural language classroom. It also considers the possible impact that different kinds of visual materials may have on the reception of learning content by learners.

Our work on the meaning and use of visual material draws on Kress \& Van Leeuwen (1996) on the "grammar of visual images". Their theory is premised on the extended use of visual material in communication that can be related to the development of new technologies in the past 10 to 15 years. In this study we consider current teaching and learning practices where visual images are used in materials in language classrooms. The investigation made two assumptions concerning current teaching of English as a first (now referred to as primary) and second (now referred to as first additional) language in South Africa: first, more visual material is used in language teaching and learning now, and second, in language learning materials visual images of people are more representative than before 1990 of the full range of cultural and ethnic groups in the country.

For some time many teachers in English language classrooms in South Africa have supplemented the available textbooks with materials they developed themselves. Changes resulting from the move to democracy since 1990 increased the move towards a more inclusive school curricula. These have required the development of new learning materials that are more varied than standard language textbooks ${ }^{1}$. This has often meant that teachers selected material relevant to a 
given topic and prepared worksheets from a variety of textbooks. An incident that occurred in a language classroom recently is recorded here to illustrate that the process of adding visuals requires careful consideration.

For this lesson on the grammatical forms of reported speech in English a particular set of visual images were used of children who had clearly ,black', or alternatively, ,creole' features (Figure 1). The material had specifically been selected in consideration of such images which represent the diversity of the South African population. The reponse to these images was unexpected. One learner made the loud and indignant comment that he had had enough of this ,new South Africa stuff' being shoved down his throat. Others in the class indicated their support for his view. What seemed an obviously racist position prompted questions regarding the selection and use of visual material. On the one hand it seems obvious that there is a need for material (i) that will support and elaborate the verbal textual message, and (ii) that will enhance learning of language as well as of interpersonal and intercultural ethics by the messages coded overtly and covertly in the images. On the other hand, the learners' responses illustrate how difficult it is to predict whether visuals selected for a lesson will facilitate or interfere with learning. Whether learners actually found the images offensive or not, they all reacted to the first objection and the intended focus on forms of reported speech became obscured.

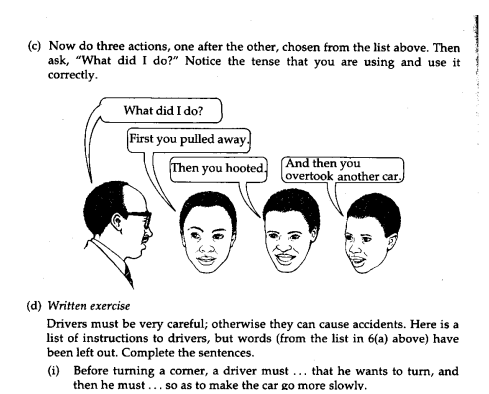

Figure 1. Visual images from Sadler, et al. 1987:14.

Images, like words, have connotations. What offends and alienates one group in a multicultural learning environment, may please and engage another. Improved insight into how visuals estrange or co-opt readers in the learning process could help to determine the kinds of visuals that will assist in developing English language skills that contribute to improved educational opportunities and better employment prospects. It may also provide more information on aspects of intercultural communication that are pertinent to the multilingual, multicultural educational context of the new South African democracy. We hoped that a survey of learner responses could offer insights into (i) which kinds of visuals could trigger negative responses (and possibly retard or impede the learning process), (ii) which kinds of visuals could trigger positive responses and thus support or encourage the learning process, (iii) how visuals could assist in challenging and changing socially questionable prejudices in an educationally sound way.

The following basic research questions directed an empirical investigation into learners' responses to the "grammar of visual design" used in language learning material:

1. What are learners' views of the role and usefulness of textbook illustrations in general and English textbooks in particular? 
2. How do learners respond to specific variables such as age, gender, race, style of representation, and so on, in pictures of people that one might find in English textbooks?

3. How do these responses inform us on the ability of visuals to hinder or facilitate and motivate language learning?

\section{THEORETICAL FRAMEWORK - THE MEANING OF VISUAL IMAGES}

In designing a questionnaire that would assist in finding answers to these questions, we referred to Kress and Van Leeuwen (1996). We also referred to work done quite a bit earlier by Rune Petterson (1989).

In establishing a theoretical framework, Kress \& Van Leeuwen provided the following useful pointers: (i) for a time the visual aspects of texts were regarded as secondary or even inferior to the verbal, but this perception is now strongly challenged; (ii) currently there is a growing awareness of visual images as part of a powerful semiotic system separate from, even if linked to, the verbal; (iii) recent advances in technology have encouraged and facilitated increased use of visual images in texts; (iv) certain kinds of information may be more directly communicated, more easily understood and cognitively better processed through visual media rather than through a verbal mode of communication. Explicit or implicit acceptance of these premises has given rise to extended inclusion of visual images in teaching materials. These insights have also brought about greater appreciation of the educational value (as opposed to mere accentuation or entertainment value) of visuals in language textbooks.

Rune Petterson's work (1989) focuses on visuals designed for the purpose of conveying information. He considers the role of the viewer in determining how effective visual communication will be. He works with the notion of viewer frames and reflects on cognitive and physical processes involved in the acts of picture perception and interpretation. We used a model of communication that Petterson drew on Schramm (an adaptation of Shannon \& Weaver's model) to investigate, noise' that may interfere in communication. Just as paralinguistic features, such as a screeching voice, may hinder a listener's ability to hear the message, seemingly inconsequent features of images may interfere with the perception of the viewer. Our particular interest was to gain information on these kinds of interferences, the visual equivalent of ,noise', from the field of experience of the intended users of learning material. Petterson suggests that instructional material is often designed with the counterpart of the producer in mind as implied reader, rather than the most probable reader, namely one of the learners. Then, communicative breakdown can result from diminished overlap of experience between producer and receiver. Differences of age, gender, culture, race, class, affinity to styles of representation, and the likes need to be considered in producing visuals for learning materials.

Petterson (1989) argues that the following factors may influence perception:

* current cultural and social status

* time and stage of development

* receiver's mood, experience, memory

He finds that all the aspects that combine to form a picture, contribute to its perception. This implies that attitudinal aspects of images can be manipulated by the text producer, and will codetermine how these images will be interpreted. This view seems to be compatible with what Kress and Van Leeuwen (1996) refer to as the "grammar of visual design" where visual elements such as line, colour, framing, perspective and size are understood to combine in making meaning. 


\section{RESEARCH METHOD - FINDING THE RIGHT QUESTIONS, ATTENDING TO REAL READERS}

In designing a questionnaire that could test learner responses to attitudinal aspects of images more systematically than a chance encounter during a lesson on reported speech forms, we collected samples of visuals actually used in grade 10 textbooks that had recently been prescribed works, and are currently being used in the process of preparing materials for the new curriculum. A set of visuals resembling such English textbook material was compiled by using scanned images, clipart and imitation text. The selection was based on the types of pictures representing people in real English school textbooks used in local classrooms. The research procedure was to obtain written responses to these samples that resemble learning materials that learners would be familiar with. The written responses were checked by interviews and discussion. The aim was first to check the validity of the claims made by Kress and van Leuwen (1996) and Petterson (1989) in this particular educational context, and second to suggest guidelines for introducing and if necessary adapting language teaching and learning materials with a strong visual component.

The layout and text of the sample set used in the questionnaire resembled typical language exercises and passages for reading. The written text was deliberately not meaningful in order to exclude any influence the content of the verbal part may have had on the responses to the visuals. In a number of ways the material used in the project differed from authentic material, e.g the page format was larger than the regular A5 size of textbooks, picture size was also slightly larger than in authentic material, no colour was used in lines or in shading, etc. Using such compiled material rather than books or worksheets actually in use ensured a greater degree of control over the variables we selected. The research was of course limited by the kinds of reproduction technology at disposal of researchers; however, this is negligible as most of the schools that produce their own learning materials operate under similarly limited circumstances.

Responses were obtained by means of a set of three different questionnaires. The first collected information on the particulars of each respondent: they were asked to give their name, gender, schools attended, home town, and also give details of their reading habits and their experience of school textbooks. The second was made up of questions to be answered in response to three sets of constructed material, and the third asked questions to be answered in response to examples of authentic material (cf. Appendix for a copy of the first two questionnaires). The first questionnaire set the parameters within which analysis of the responses could make legitimate findings. It gave the average age, gender distribution, level of education, linguistic background and linguistic repertoire of the full group of respondents. This paper will largely report on and give an analysis of the responses to the second questionnaire. The third questionnaire, not appended, gave images of pages with verbal text organised in more and less dense ways. This was to check whether conventional typewritten texts with minimal or no visual aids to the organisation of the content may be more attractive to learners than those that make ample use of visuals.

The selected visual material made use of pictures of people, as the most interesting emotional responses encountered previously appeared to have been in relation to visuals of people. Six significant areas were identified in which it appears that an illustrator has a choice ${ }^{2}$ in the manner of representation of people. Images of human participants represent, and thus may vary according to, the following visual features: (i) gender, (ii) race, (iii) age, (iv) socio-economic class, (v) direction of gaze, and (vi) the style of representation (photo, cartoon, naturalistic drawing, etc.). 
As respondents there were 77 grade 10 learners (aged 15-16 years) in a historically white high school, open to all races since 1990 . The school is situated in an area closest to traditionally white and mixed-race (,coloured') communities. All of the learners have Afrikaans as their first language. Among the respondents there were differences of gender (50\%:50\%), race (66\%:33\%), and socio-economic position identified in terms of parents' level of education and employment ${ }^{3}$. Racial differences were between white and mixed-race groups ${ }^{4}$. There were no black respondents at the school since Afrikaans was the language of learning in the school ${ }^{5}$. Although English is a compulsory subject, the school offers a choice between taking it as primary language or as an additional language.

The data were collected during 50-minute class sessions with one English-as-a-primary-language group and one English-as-a-first-additional language group, respectively. Each learner was handed a set of material and questionnaires. One researcher was present throughout to monitor the process and to advise on procedural matters. On the following day she had another 50 minute session with each group in which she discussed and obtained oral clarification on some of the comments learners had made.

\section{RESEARCH RESULTS - WHO TO BELIEVE, WHAT TO MAKE OF THE ANSWERS}

Questionnaire One provided information on the demographics of the group of respondents, on their reading habits, and on their perception of the value of visuals in learning material generally, and in English textbooks specifically.

Of interest to us here, are the responses we got to questions 14 and 15 (cf. p.1 of the questionnaire). Tables 1 and 2 show the summarised responses, which confirm that generally learners find visuals in school textbooks helpful and interesting. This contradicts a perception that pictures belong in primary school books, or that they simply fill space so that readers need not pay proper attention to the visual content. In English textbooks the learners believe visuals have an explanatory function, adding to the written text and so giving more than simple repetition. Almost one third of the learners indicated that visuals also have an aesthetic function in that they are judged to be ,decorative'.

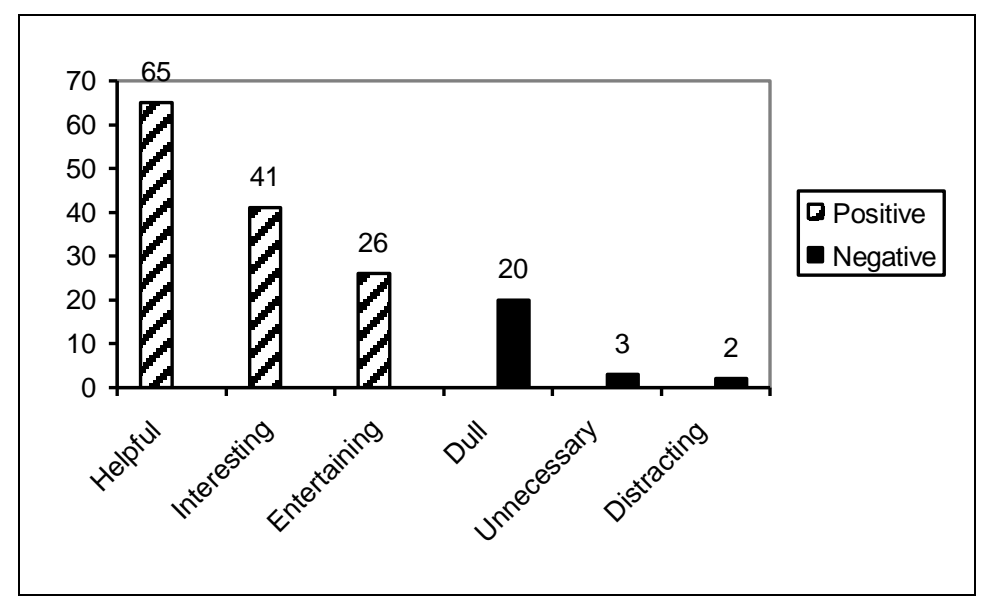

Table1: Experience of schoolbook pictures 


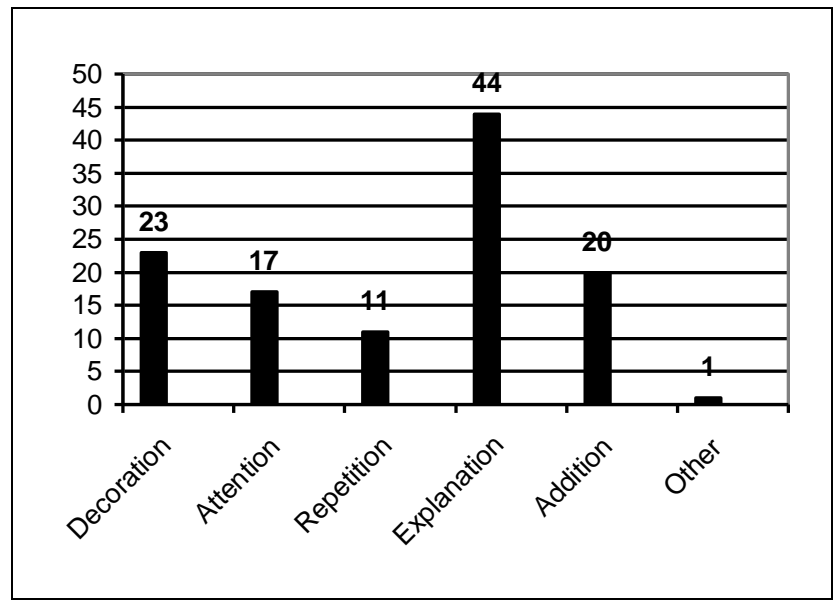

Table 2: The purpose of pictures in English textbooks

Questionnaire Two gave information on which kinds of visuals respondents preferred and it gave insight into the reasons for their preferences. Such preferences were taken as indicators of how attitudinal aspects of the images were interpreted. The compiled material was made up of three sets of contrasting visuals, each intended to oppose two particular variables, namely age and socioeconomic class (Set 1), direction of gaze and gender (Set 2) and style of representation and race (Set 3). Table 3 summarises the different subcategories represented in the various sets of visuals.

\begin{tabular}{|c|c|c|c|}
\hline \multicolumn{4}{|c|}{ Set 1} \\
\hline & & Age & Socio-economic class \\
\hline \multirow[t]{2}{*}{$1 \mathrm{~A}$} & (a) & Teenagers & Upper class \\
\hline & (b) & Adults (and elderly) & Upper (business) class \\
\hline \multirow[t]{2}{*}{$1 \mathrm{~B}$} & (a) & Teenagers & Lower class \\
\hline & (a) & Adults & Lower class \\
\hline \multirow[t]{2}{*}{$1 \mathrm{C}$} & (a) & Teenagers & Sports \& entertainment \\
\hline & (b) & Little children & Sports \& entertainment \\
\hline \multicolumn{4}{|c|}{ Set 2} \\
\hline & & Eye-contact & Gender \\
\hline \multirow[t]{2}{*}{$2 \mathrm{~A}$} & (a) & Eye-contact/ gaze towards reader & Female \\
\hline & (b) & Face/gaze turned away from reader & Female \\
\hline \multirow[t]{2}{*}{ 2B } & (a) & Eye-contact/ towards reader & Male \\
\hline & (b) & Face/gaze turned away & Male \\
\hline \multirow[t]{2}{*}{$2 \mathrm{C}$} & (a) & Eye-contact/ towards reader & Male \& female \\
\hline & (b) & Face/gaze turned away & Male \& female \\
\hline \multicolumn{4}{|c|}{ Set 3} \\
\hline & & Drawing Style & Race \\
\hline \multirow[t]{2}{*}{$3 \mathrm{~A}$} & (a) & Naturalistic & Black \\
\hline & (b) & Cartoons & Black \\
\hline \multirow[t]{2}{*}{$3 \mathrm{~B}$} & (a) & Naturalistic & White \\
\hline & (b) & Cartoons & White \\
\hline \multirow[t]{2}{*}{$3 \mathrm{C}$} & (a) & Naturalistic & Multi-racial \\
\hline & (b) & Cartoons & Multi-racial \\
\hline
\end{tabular}

Table 3: Breakdown of variables tested

Learner responses to Set 1 indicated a clear preference for visuals representing the peer group of the learners: $76 \%$ of the respondents preferred representations of teenagers as opposed to representations of adults, and $56 \%$ preferred representations of teenagers as opposed to 
representations of young children. Here an interesting gender difference was apparent: of the 31 respondents who liked the representations of smaller children, the majority were girls.

Confronted with a choice between ,smartly dressed middle class' characters and „working class' characters in casual clothes, whether they were youngsters or adults, the respondents found the working class representations more trendy and thus preferable. Figures $2 \mathrm{a}$ and $2 \mathrm{~b}$ show the opposition between middle class and working class youngsters; Figures $3 \mathrm{a}$ and $3 \mathrm{~b}$ show the opposition between professional and working class adults. In the written responses positive comment was made of characters engaged in sporting activities. One or two were not comfortable with the image of an adult as domestic worker, and one expressed uneasiness with the image representing graffiti artists at work as she felt this put people of her own age in a bad light.

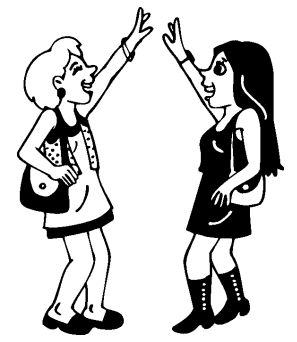

Figure 2a

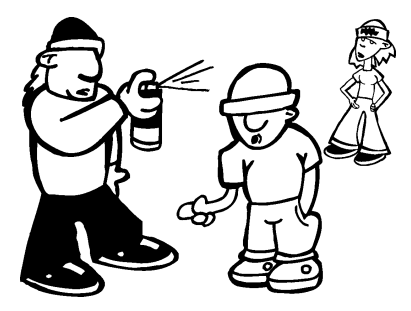

Figure 2b

The opposition between middle class and working class youngsters

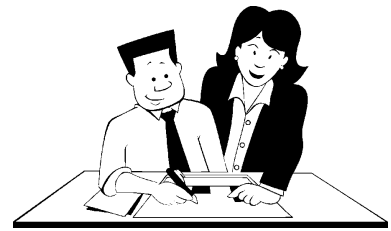

Figure 3a

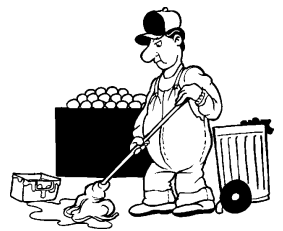

Figure 3b

The opposition between middle class and working class adults

Learner responses to set 2 indicated marginal preference for images with the gaze directed to the reader. Written comments revealed that facial expression was more important than the direction of gaze. Learners showed sensitivity to expressions of friendliness, surliness, indifference, and so on. Interestingly, they paid limited attention to gender. The preference female respondents showed for images of women or girls is insignificant. Figures $4 \mathrm{a}$ and $4 \mathrm{~b}$ illustrate the difference between gaze directed at the reader and gaze directed elsewhere.

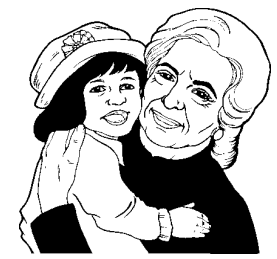

Figure 4a

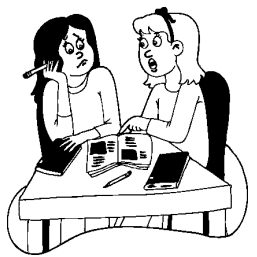

Figure 4b

The opposition between gaze directed at the reader and gaze directed elsewhere. 
Learner responses to Set 3 indicated a clear preference for cartoon style images over a naturalistic style. Figures $5 \mathrm{a}$ and $5 \mathrm{~b}$ illustrate the cartoon style, and Figures $6 \mathrm{a}, 6 \mathrm{~b}$ and $6 \mathrm{c}$ illustrate the naturalistic style. In the analysis specific attention was directed at preferences in images where racial differentiation was clear. A breakdown was made of preferences according to the racial categories of respondents themselves; an overall preference for multiracial groups was apparent. Otherwise, learners appeared to favour images representing their own group above any other, with both groups showing least affinity for the group not represented in their school at all.

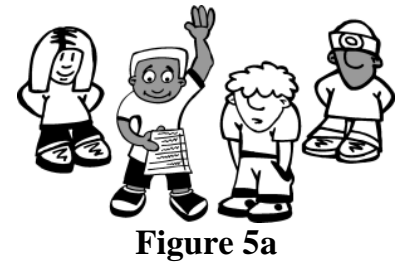

\section{Cartoon style}

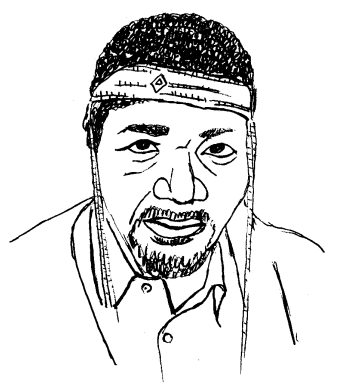

Figure 6a

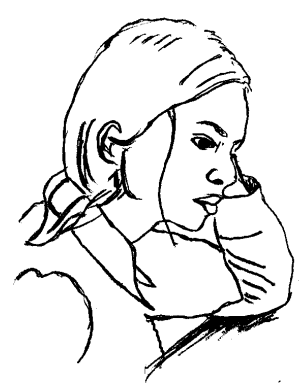

Figure 6b

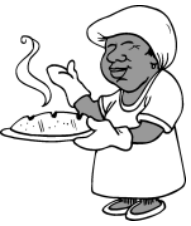

Figure 5b

\section{Naturalistic style}

Table 4 summarises the responses learners gave to Figures $6 \mathrm{a}, 6 \mathrm{~b}$ and $6 \mathrm{c}$. In their written comments the mixed-race respondents made no negative remarks to justify their choice. Of the white respondents 6 out of 58 did not like the page with images of blacks only, while 4 specifically commented positively on images reflecting racial diversity.

\begin{tabular}{|l|c|c|c|c|c|c|}
\hline & \multicolumn{2}{|c|}{ Black } & \multicolumn{2}{c|}{ White } & \multicolumn{2}{c|}{ Multi-racial } \\
\hline & $\begin{array}{c}\text { Strong } \\
\text { preference }\end{array}$ & $\begin{array}{c}\text { Strong } \\
\text { dislike }\end{array}$ & $\begin{array}{c}\text { Strong } \\
\text { preference }\end{array}$ & $\begin{array}{c}\text { Strong } \\
\text { dislike }\end{array}$ & $\begin{array}{c}\text { Strong } \\
\text { preference }\end{array}$ & $\begin{array}{c}\text { Strong } \\
\text { dislike }\end{array}$ \\
\hline $\begin{array}{l}\text { Coloured } \\
\text { respondents }\end{array}$ & $33 \%$ & $26 \%$ & $22 \%$ & $40 \%$ & $44 \%$ & $33 \%$ \\
\hline $\begin{array}{l}\text { White } \\
\text { respondents: }\end{array}$ & $3 \%$ & $36 \%$ & $47 \%$ & $32 \%$ & $50 \%$ & $32 \%$ \\
\hline
\end{tabular}

Table 4: Racial preferences 
Overall, the six variables selected as potentially critical features in evoking responses to visuals turned out to be of less significance than some others that were introduced, but not set up contrastively. In many cases learners' evaluations indicated that features which were not considered separately, had had a greater affective impact than some of the ones explicitly and calculatedly introduced. The words or expressions learners chose to articulate the non-verbal message that they felt had been communicated were particularly telling. The analysis indicated that the activities characters were engaged in, were most prominent in affecting learners' preferences: much comment was centred on representations of characters singing, making music, roller-blading, spray-painting or doing sport. Further, learners were engaged by the style of representation (e.g. pencil sketch/cartoon/etc.), commenting on ,para-semiotic' aspects such as colour (or absence of interesting use of colour), thickness of the lines, size of an image, and so on. General evaluative comments distinguished between impressions of what was ,interesting' and „fun' as opposed to „,boring' and 'dull'. Rather than the direction of gaze, learners attended to facial expressions which they read e.g. as being happy, depressed, and so on. Other features learners identified as significant referred to whether the picture represented some ,story' which ,made sense', and whether the image appealed to their sense of humour. Age, race and gender were recognised, but rarely interpreted as dominant features.

A summary of the overall preferences of the 3 sets indicates that visual images of casual, active teenagers are most likely to evoke positive responses, and that happy and funny faces are preferred to sad or expressionless ones. Cartoons representing multiracial groups are preferred to naturalistic sketches of ,all whites' or ,all blacks'. Thus, we are justified in assuming that visual images are significant components of texts used in language classrooms. We are also justified in suggesting that due attention should be paid to attitudinal aspects of visual images. Most likely to facilitate learning would be visuals representing teenagers in cartoon style, where characters are engaged in ,attractive activities' (DJ-ing, painting graffiti, playing football, etc.) and where they are representative of a variety of racial groups. Most likely to become barriers to learning would be visuals representing adults in naturalistic sketches. For a limited and predictable number of respondents aspects of gender and race may be prohibitive. To address prejudices of such a nature an integrated social awareness approach is required. Simply changing the visual material to suit parochial or partisan preferences is not advisable. On the other hand, prejudiced responses of some learners that do not represent general patterns should not be directive in the selection of suitable images.

Questionnaire 3 gave information that would confirm or refute some of the conclusions drawn from questionnaires 1 and 2. Particularly, it gave additional information on the usefulness of visuals in textbooks. There was an overwhelmingly negative response to a full page of densely written text with no visuals such as is standardly used for novels. Comments here included the following:

I'm so not in the mood for this. It looks boring.

I start planning the rest of the day.

Oh my G--, just shoot me.

Help!!!!!!!!!!!!!!!!!!!!!!!!!!!!

The less dense, written text with more visual guidance in the lay-out (e.g. bold headings, indented paragraphs, use of italics) was found to be an improvement, but still almost a quarter of the group found this second text as bad as the first. 
Asked whether they read images or written text first, 8 indicated that they start reading before looking at the image; 67 said they did not ignore the picture. Commenting on what good pictures do, the most significant responses were that they „tell more about story', „help one visualise what it is about', make it more interesting or fun, attract the reader's attention and make the reader curious so that $\mathrm{s} /$ he will want to find out more.

Asked about their attitudes to exercises which require interpreting visual images, 61 said they liked such exercises, 10 did not and 3 were neutral or ambiguous. The reasons learners gave for liking exercises based on visual communication included that it is „fun', „interesting', „easier', more explanatory, provides concrete assistance, encourages creativity and allows freedom in interpretation. Those who disliked such exercises complained that visual images are open to misinterpretation, require too much time and effort, or that they are childish and don't teach anything.

\section{CONCLUSION ... SO WHAT?}

To some extent learner assessment of visual images has confirmed what has already been established, namely that visuals do in fact encourage and facilitate learning. Even in English language learning pictures are valued more for their assistance in mastering content than for their motivational function. The decorative, entertainment, and attention-grabbing functions of visuals were consistently rated as secondary.

There is no doubt that visuals do carry connotative meaning, and that they are not ideologically neutral. Learners' preferences reflect their cultural context: it appears that teenagers prefer to be addressed by peers, whether the medium is verbal or visual. The group we interviewed emphasised an interest in sporting activities and entertainment. The focus on entertainment could be related to their expressed preference for cartoon style. The preference for multiracial pictures certainly reflects political sensitivity in respect of the recent history of the larger community, as does the limited gender sensitivity among some of the girls who responded.

The outcome of this project has raised a number of further questions, such as

* How will learners respond to a greater variety of styles, photographs, improved sketches, more colour, different cartoon styles, i.e. to more of the new media?

* How do learners decide on what is identified as „formal', „funky”, ,cool', „boring', etc.?

* Would learners from different communities use different measures? - What is „cool' to one group may be ,uncool' to another.

* How do learners use pictures to make better sense of texts?

* How may the communicative use of language be improved by visuals?

* How could visuals become instrumental in reinforcing and maintaining or challenging and changing values?

* How do visuals reflect changing values, changing patterns of learning, etc.?

It is clear that improved technology as well as new media that introduce more visual images in texts than ever before, have changed the ways learners receive information and how they learn. Work started in 1994 by the New London Group, the International Multiliteracies Project, which focuses on the pedagogy of multiliteracies, already introduced the idea of a 
changed perspective on what constitutes literacy in a world where new technologies are increasingly introduced ${ }^{6}$.

This study has highlighted a need for more extensive investigation into differences in responses to visuals that may be related to cultural, socio-cultural, and demographic differences in our region. A number of studies have been done on the preparation of youngsters for learning literacy (Cf. Bloch, Stein \& Prinsloo, 2001). Similar studies on preparing youngsters for learning visual literacy, need to be undertaken. The impact of home and classroom environment on ways of interpreting visuals also needs scholarly attention ${ }^{7}$. Preparatory work is already underway for taking questionnaires similar to the ones used in this project to schools where the educational context is significantly different to the one reported here. We would like to compare the responses discussed in this paper to responses of learners in historically black schools where, on average, community literacy is more rudimentary than in most white or mixed-race communities. We shall also compare the responses of learners in rural communities to those in urban communities. So, the end is but the beginning.

\section{NOTES}

${ }^{1}$ Grade 10 (formerly Standard 8) textbooks that are used in this way, to which this research referred, include Brooks et al (1989), Sadler et al (1981) and Sadler et al (1987).

${ }^{2}$ Similar to the way in which speakers have different stylistic choices that carry associated representational and connotative meanings, illustrators can choose between various styles and achieve various kinds of meaning .

${ }^{3}$ In this case we were obliged to generalise on the educational and employment status of parents on the basis of the suburb where respondents live, as on ethical grounds we did not include questions asking such sensitive questions.

${ }^{4}$ Although one would prefer not to categorise in terms of racial classification, the recent history of social divisions on these grounds in education and elsewhere, have made this pertinent. Hopefully research of this kind will assist in redressing inequalities that may still exist.

${ }^{5}$ The research project will continue, taking similar material and questionnaires to schools where different historic, racial, linguistic and socio-economic circumstances prevail.

${ }^{6}$ Cope \& Kalantzis (1998) summarized the ,multiliteracies argument' as: “our personal, public and working lives are changing in some dramatic ways, and these changes are transforming our cultures and the ways we communicate. This means that the way we have taught literacy, and what counts for literacy, will also have to change".

${ }^{7}$ Work undertaken in the Children's Early Literacy Learning (CELL) research project in Gauteng, Northern Province and the Western Cape, SA deserves to be mentioned here.

\section{REFERENCES}

BLOCH, C, P STEIN \& M PRINSLOO. 2001. Progress report on children's early literacy Learning (CELL) research project in South Africa. Journal of Early Childhood Literacy, 1(1): 121-122.

BROOKS, BH, AG THRUMAN, DB WYLDE, F D'YMANT, MA CUNNINGHAM, NJ STEAR \& SP GOSHER. 1989. Insights: English first language. Kenwyn, Cape Town: Juta. 
COPE, B \& M KALANTZIS. 1998. Putting multiliteracies to the test. In Education Australia Online http://www.edoz.com.au/educationaustralia/edoz/archive/features/mult1.html)

COPE, B \& M KALANTZIS (Eds) 1999. Multiliteracies: Literacy learning and the design of social futures. London, New York: Routledge.

KRESS, G. \& T VAN LEEUWEN. 1996. Reading images: the grammar of visual design. London: Routledge.

PETTERSON, R. 1989. Visuals for information: research and practice. New Jersey: Educational Technology Publications.

SADLER, MJ, B SCHEFFLER \& V RODSETH. 1987. A book of English for standard 8. Pretoria: Kagiso Publishers.

SADLER, RK, TAS HAYLLAR, CJ POWELL. 1981. Senior language. South Melbourne: Macmillan Education Australia.

Images from CorelDRAW® 9. Used under license. IMSI Masterclips. 1997. Vector Images (WMF)

\section{Biographic Note}

Dr Christine Anthonissen and Ms Monica Kirsten are at the Department of General Linguistics at the University of Stellenbosch. Both have a strong interest in Applied Linguistics. Email: ca5@sun.ac.za 


\section{APPENDIX}

\section{Questionnaire 1 (Background)}

1. Name:

2. Sex:

3. Surname:

4. Age:

5. Residential area:

6. Town:

7. Primary school:

8. Home language:

9. School English First / Second Language?

10. Average school achievement:

$\square \mathrm{A} \square \mathrm{B} \quad \square \mathrm{C} \quad \square \mathrm{D} \quad \square \mathrm{E} \quad \square \mathrm{F} \quad \square \mathrm{G}$

11. How much do you read?

$\square$ Very much

$\square$ A little

$\square$ A lot

Very little

$\square$ Not very much

12. What do you read most often, whether you want to or not? Number the following from what you read the most (1) to what you read the least (10). Don't say what you like most. Say what you actually read most.

Comics

Internet sites with lots of visuals

Internet sites with mostly plain text

Magazines

Newspapers
Non-fiction books with pictures

Non-fiction books without pictures

Novels

School textbooks

Other (Specify)

13. In which of your subjects do the textbooks / worksheets have the most pictures?

14. The pictures in textbooks and on worksheets are (Mark as many as are relevant.)
$\square$ Distracting
$\square$ Dull
Interesting
$\square$ Entertaining
$\square$ Helpful
Unnecessary

15. What do you think is the general purpose of the pictures in English textbooks / worksheets?

$\square$ Decoration

$\square$ To repeat what the text says

$\square$ To add information that is not in the text
To explain the text

To draw attention

$\square$ Something else (Specify) 


\section{Questionnaire 2 (Preferences)}

\section{Set 1}

1. Compare the two sheets in each pair. Tick the one you prefer for each pair.
Set $1 \mathrm{~A}$
(a) $\square$
(b) $\square$
Set 1B
(a) $\square$
(b) $\square$
Set $1 \mathrm{C}$
(a) $\square$
(b) $\square$

2. Take the 3 sheets that you selected above. Now select the 1 that you prefer the most. Write down its number on the line:

3. Say why you prefer this one. You may answer by comparing it to some of the other sheets if you want to.

4. Take the 3 sheets that you did not like. Now say which one you liked the least. Write down its number on the line:

5. Say why you don't like this one. 


\section{Questionnaire 2 (Preferences)}

\section{Set 2}

6. Compare the two sheets in each pair. Tick the one you prefer for each pair.
Set $2 \mathrm{~A}$
(a) $\square$
(b) $\square$
Set 2B
(a) $\square$
(b) $\square$
Set $2 \mathrm{C}$
(a) $\square$
(b) $\square$

7. Take the 3 sheets that you selected above. Now select the 1 that you prefer the most. Write down its number on the line:

8. Say why you prefer this one. You may answer by comparing it to some of the other sheets if you want to.

9. Take the 3 sheets that you did not like. Now say which one you liked the least. Write down its number on the line:

10. Say why you don't like this one. 


\section{Questionnaire 2 (Preferences)}

\section{Set 3}

11. Compare the two sheets in each pair. Tick the one you prefer for each pair.
Set 3A
(a) $\square$
(b) $\square$
Set 3B
(a) $\square$
(b) $\square$
Set $3 \mathrm{C}$
(a) $\square$
(b) $\square$

12. Take the 3 sheets that you selected above. Now select the 1 that you prefer the most. Write down its number on the line:

13. Say why you prefer this one. You may answer by comparing it to some of the other sheets if you want to.

14. Take the 3 sheets that you did not like. Now say which one you liked the least. Write down its number on the line:

15. Say why you don't like this one. 